\title{
Asymmetric or diffusive co-evolution generates meta-populations in fig-fig wasp mutualisms
}

\author{
WANG RuiWu ${ }^{1 *},{\text { YANG } \text { Yan }^{1} \& \text { WIGGINS Natasha L. }}^{2}$ \\ ${ }^{1}$ State Key Laboratory of Genetic Resources and Evolution, Kunming Institute of Zoology, Chinese Academy of Sciences, Kunming 650223, \\ China; \\ ${ }^{2}$ School of Plant Science, University of Tasmania, Hobart 7001, Australia
}

Received April 13, 2013; accepted November 25, 2013; published online May 13, 2014

\begin{abstract}
Co-evolutionary theory assumes co-adapted characteristics are a positive response to counter those of another species, whereby co-evolved species reach an evolutionarily stable interaction through bilateral adaptation. However, evidence from the fig-fig wasp mutualistic system implies very different co-evolutionary selection mechanisms, due to the inherent conflict among interacted partners. Fig plants appear to have discriminatively enforced fig wasps to evolve "adaptation characteristics" that provide greater benefit to the fig, and fig wasps appear to have diversified their evolutionary strategies in response to discriminative enforcement by figs and competition among different fig wasp species. In what appears to be an asymmetric interaction, the prosperity of cooperative pollinating wasps should inevitably lead to population increases of parasitic individuals, thus resulting in localized extinctions of pollinating wasps. In response, the sanctioning of parasitic wasps by the fig should lead to a reduction in the parasitic wasp population. The meta-populations created by such asymmetric interactions may result in each population of coevolved species chaotically oscillated, temporally or evolutionarily.
\end{abstract}

asymmetric co-evolution, inter-specific cooperation, meta-population, mutualism

Citation: Wang RW, Yang Y, Wiggins NL. Asymmetric or diffusive co-evolution generates meta-populations in fig-fig wasp mutualisms. Sci China Life Sci, 2014, 57: 596-602, doi: 10.1007/s11427-014-4653-y

Co-evolution, which was once previously assumed to be a rare form of evolution, is now recognized as a common existence within ecosystems, with either strong or weak interactions between species [1,2]. By definition, coevolution requires that two species adapt to evolutionary changes occurring in each other [1-3]. An example of reciprocal adaptation is the development of mutualistic relationships between plants and pollinating insects. As a plant develops a specialized structure and/or organ to provide a pollinator with food or a living habitat, as in many obligate mutualistic systems, the pollinating species develops a pollen carrier mechanism to disperse pollen, which could evolve as a species-specific interaction [4-6]. In antagonistic interactions

*Corresponding author (email: ruiwukiz@ hotmail.com) between species, for example, between plants and herbivores, both species co-evolve strategies enabling coexistence with one another-a plant may develop chemical defenses to reduce herbivory, but a herbivore may develop "counter weapons" that enable continued consumption of the plant [7]. In these well-accepted perceptions of the concept of co-evolution, co-evolved species are assumed to interact symmetrically, where the coevolved species have equally developed the biological characteristics in the same evolutionary pathway to adapt to each others' strategies $[8,9]$. Coevolved species will evolve to be in a state of equilibrium under such a symmetric interaction. Where there is a positive adaptation between two species, these will attain an evolutionarily stable strategy (ESS) through a "contract" $[10,11]$. The evolutionary characteristics of the co-evolved 
species could increase their fitness, which therefore should be the predominant strategy of the interacting species [12].

The evolutionarily stable interactions of co-evolved species are based on the assumption that species are symmetrically co-evolved. This may hold for many species interactions, but recent advances in knowledge of obligate mutualisms (e.g., fig-fig wasp, legume-rhizobium and yucca-yucca moth systems) imply that the co-evolved species are asymmetrically interacted [13-16]. In asymmetric interactions, the sanctioning of parasites by hosts that reward cooperative species will enforce the evolution of less virulent parasites, or perhaps enforce parasites to become more cooperative towards the host plant. In the fig-fig wasp system, parasites include non-pollinator wasps and the cheating individuals of pollinator wasps, by definition [17]. However, in asymmetric interactions, symbionts tend to diversify their strategies, which may be cooperative (e.g., the cost of carrying pollen for a host-derived reward) or may involve cheating/parasitizing the host plant (e.g., no cost of carrying pollen but this may result in being sanctioned by the host) $[14,18,19]$. Symbionts might also diversify into different cryptic species or even distinct species because of intra- or inter-specific competition, or undergo niche separation $[14,15,18]$.

In such asymmetrically co-evolved interactions, where symbionts have diversified their genotype, phenotype and/or behavioral strategies to increase their fitness, the host plant may also diversify its strategies (e.g., different sanction strategies) to facilitate the evolution of cooperation. This has been empirically observed in a fig-fig wasp system [14] and implied in other mutualistic systems [13,15,20]. In such asymmetric interactions, because both interacted species use mixed strategies of either cooperating or competing with each other, sanctioning by the host plant is predicted to lead to localized population declines or extinctions of the symbiont, thereby creating meta-populations. Populations of interacting species might temporally or evolutionarily oscillate chaotically, with population oscillation swings dependent on the plant's sanctioning intensity and competition intensity amongst the different genotypes or phenotypes within or between species. Here, we discuss a fig-fig wasp system to illustrate how asymmetric interactions between species may lead to the creation of a meta-population effect.

\section{Biology of fig-fig wasp systems}

In the obligate mutualism between figs and their pollinator wasps, the wasps carry pollen from mature syconia (enclosed inflorescences) to receptive syconia, and figs provide pollinators with access to some of their female flowers to oviposit. The larvae of pollinator wasps develop into adults in galled female flowers. Adult female wasps that develop in the syconia then disperse the fig's pollen. Both pollen dispersion (from mature syconia) and pollen availability (to receptive syconia) are dependent on the species-specific pollinator wasps [21,22]. Recent experimental results demonstrated that both pollinator and non-pollinator wasps can successfully deposit their eggs and develop to adulthood in the ovules of (fig) female flowers without pollination occurring [23]. However, figs have the ability to sanction pollen-free wasps through the abortion of syconia or by discriminatively decreasing the offspring development ratio of wasps [14,24,25].

Figs may inadvertently support cheating individuals of pollinator wasps or non-pollinator wasps that are either parasitoids of fig wasps or resource competitors (i.e., gall makers or inquilines) [26,27]. Gall makers that do not carry pollen to receptive syconia are non-pollinator wasps and cheating individuals of pollinator wasps [14,27]. Gall makers may additionally impose a negative impact on fig viable seed production by directly foraging on seeds or competing with pollinator wasps for female flowers [27-29]. The mechanisms that prevent parasites (or exploiters) from overexploiting the common resource, at the expense of the pollinator wasps and fig fitness, are still debated within the scientific community, though many hypotheses have been proposed [14,25,30-34].

Here we use the fig Ficus racemosa and the hosted fig wasp species to illustrate species interactions in the fig-fig wasp community. Ficus racemosa hosts six fig wasp species, of which one species, Ceratosolen fusciceps (Agaonidae), is the pollinator of $F$. racemosa. The species Apocryptophagus testacea and A. mayri are gall makers and compete with pollinator wasps for the common resource, i.e., the female flowers [27,35]. Apocrypta sp. and A. westwoodi are parasitoids of the gall makers A. testacea and $A$. mayri, respectively. Apocryptophagus agraensis is a parasitoid of pollinator wasps (for more details see [27,36]).

\section{Niche separation among fig wasps}

Niche partitioning, or spatial heterogeneity amongst mutualists and exploiters, has long been known to promote species coexistence [37-39]. However, niche utilization by exploiters has been observed to overlap with that of mutualists $[14,17,27]$. Niche overlap enables the possibility for one species to exclude another in the process of evolution, if either species has a fitness advantage over the other. Niche partitioning therefore does not sufficiently explain the coexistence between reciprocal mutualists, exploiters, and the stability of the system.

In $F$. racemosa, the gall-maker wasps utilize the same resource (i.e., female flowers) and temporally separate the peak of their oviposition sequence from one another. However, the oviposition periods of these species overlap and they appear to utilize the common resource at the expense of the other [14,27]. Non-pollinator gall makers are able to decrease pollinator populations, thus leading to localized extinctions in the wild $[14,29,40]$. Although niche separa- 
tion between the gall maker species of $F$. racemosa exists, the temporal segregation in the oviposition period cannot solely maintain the stability of the coexistence of these species [14,27].

\section{Asymmetric species interactions in fig-fig wasp communities}

Similar to other mutualistic systems, fig plants should sanction parasitic species and cheating individuals of pollinator wasps, and reward cooperating individuals. Selective abortion, which commonly occurs in yucca-yucca moth mutualisms $[13,41,42]$ and legume-rhizobium mutualisms $[15,43]$, also exists in fig-fig wasp mutualisms [14,23,24,44]. However, experimental evidence demonstrates that the selective abortion of syconia in $F$. racemosa only occurs when syconia are oviposited by the parasitic wasp A. testacea, which oviposits before pollinator wasps, and are thus not sufficiently pollinated by pollinator wasps $[14,44]$. Selective abortion is likely to save resources and energetic expenditure on development of syconia that are not adequately pollinated, and will consequently kill offspring of parasitic wasps within these unpollinated syconia $[14,44]$.

However, when syconia are oviposited by parasitic wasps either after they have been oviposited by pollinator wasps or by the cheating individuals of pollinator wasps, selective abortion does not occur $[14,44,45]$. The abortion of such syconia would result in the death of the pollinator wasp offspring and thus reduce the chance of pollen dispersal. In such circumstances, $F$. racemosa may use another sanctioning strategy - to discriminatively decrease the adult wasp development ratio-which occurs when the syconia are too heavily oviposited $[14,44]$. This sanctioning activity may be due to a chemical secreted by the syconia. Under sanctioning by the fig plant, exploiting individuals and non-pollinator wasps are likely to lose their fitness advantage.

Research on $F$. racemosa and related fig-fig wasp systems suggests that fig wasps have diversified their geno- types (or may have specialized and diverged into distinct wasp species) and phenotypes/behavior (by separation of oviposition peaks) in response to intra- and/or inter-specific competition among wasps, and in order to escape sanctioning or enforcement by the host fig. As a counter-response, host figs may be able to diversify their strategies in order to facilitate the evolution of less harmful and/or more cooperative wasps (e.g., through wasps dispersing more pollen and/or less parasitization). Figs can implement different strategies to sanction parasitic wasps depending on the different fig wasp strategies [14,44]. Diffusive strategies between the co-evolved species reveal that the evolution of cooperative wasps may be an enforced process due to the limited dispersal ability of symbionts and asymmetric interactions between symbiont and host, rather than positive evolution for the reciprocal exchange stemming from the idea of contract theory (Figure 1).

Among fig wasp species, non-pollinators have a fitness advantage over pollinating wasps as they do not pay the cooperative cost (i.e., carrying pollen and pollen dispersal), and might therefore be able to exclude pollinators from the system $[14,28,40]$. The non-pollinator gall-maker wasps can directly reduce pollinator wasp populations or cause localized extinctions, because of resource competition and fitness advantages over pollinator wasps $[14,44]$.

\section{Asymmetric interactions and the metapopu- lation}

The sanctioning imposed by figs, either through the selective abortion of syconia or discriminative repression of offspring development of parasitic wasps (or exploiters), is proposed to lead to population decreases and/or localized extinctions of parasitic species and cheating individuals of pollinator wasps within specific syconia, trees or habitats. Cooperative pollinator wasps would be predicted to subsequently increase in numbers through immigrating individuals, which should be encouraged by the high reward offered by fig plants, resulting in high offspring developmental

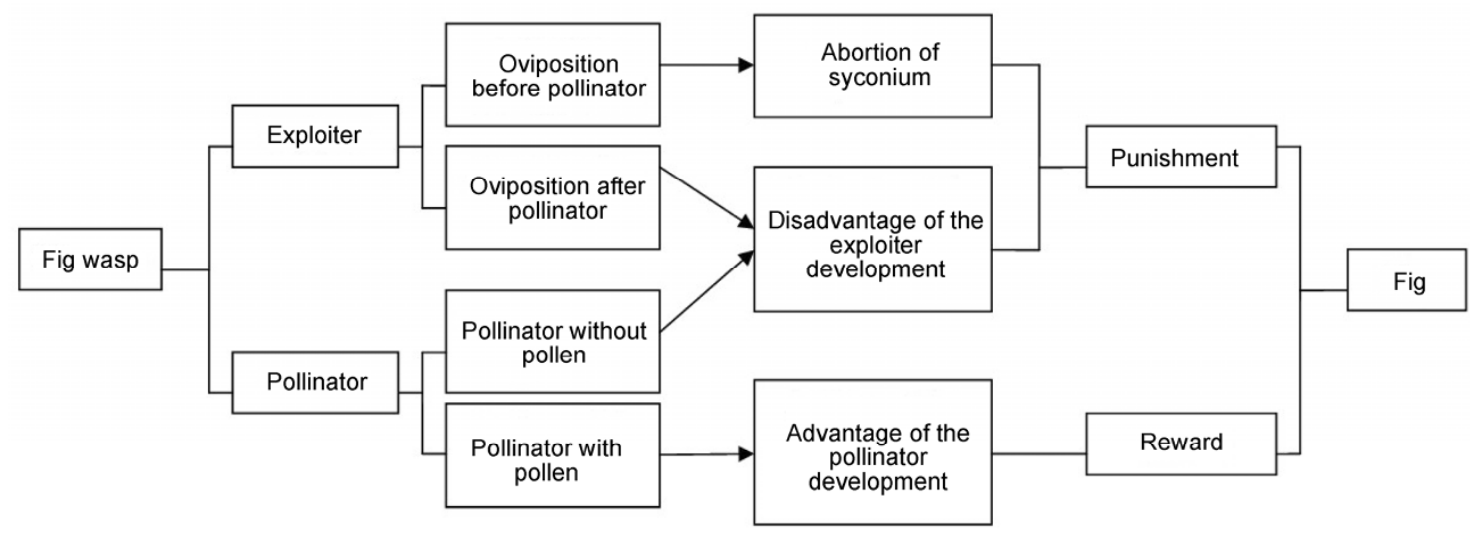

Figure 1 Asymmetric interactions in the fig-fig wasp system. 
rates. After a population of pollinator wasps becomes established, the migration of non-pollinator wasps or the offspring of cheating individuals of pollinator wasps will have a fitness advantage - as fig syconia will be sufficiently pollinated by cooperative pollinator wasps. Over time, the population of non-pollinator wasps and cheating individuals of pollinator wasps will increase, resulting once again in population declines or localized extinctions of pollinator wasps. The over-abundance of parasitic wasps that leads to the declines in pollinator wasp populations will subsequently result in inadequate fig pollination. The fig should then implement discriminative sanctioning against parasitic wasps, once again leading to population decreases or localized extinctions of parasitic wasps. Meta-populations are thus predicted to be created through such asymmetric interactions (Figure 2).

In such asymmetric interactions, each species' population is predicted to chaotically oscillate either temporally or evolutionarily (Figures 1 and 2). The population of each fig wasp species should oscillate with population establishment cycles after population declines that result from sanctioning by host fig plants or from competition exclusion between wasp species. Host fig population numbers and/or seed production may also oscillate in response to oscillations of pollinating wasp populations. Both the host plant and associated wasps populations might also oscillate evolutionarily. Over their evolutionary histories, climatic and/or geographic (spatially heterogeneous variation) shifts may be expected to favor population increases in either the nonpollinator wasps or pollinator wasp populations, followed by the establishment of some species potentially leading to the extinction of others across spatial and/or temporal scales, possibly similar to that which occurs in the yucca-yucca moth system $[18,46]$.

It has been experimentally demonstrated that the local extinction frequency of pollinator wasps differs greatly among habitat sites occupied by $F$. racemosa. In primary forest, the proportion of syconia that contained no or low numbers of pollinator wasps was much lower than that in fragmented forests [14,29] (Figure 3). In fragmented forest, more than $30 \%$ of syconia contained no pollinator wasps but sufficient pollination was observed in the dry season [29]. This finding indicates that the frequency of local extinction of pollinator wasps was due to high competition with non-pollinator wasps in fragmented forests relative to primary forests. Comparisons between primary forest, fragmented forest and locally fragmented forest habitats demonstrates that the average pollinator wasp proportion was much higher in the wasp community in primary forests compared with fragmented forests $[29,40]$. Forest fragmentation appears to favor population increases of nonpollinator wasps, which may in part be attributed to decreased predation by ants (as a result of decreased population numbers) and which in turn imposes a much higher negative impact on non-pollinator than pollinator wasps $[35,40]$, and may therefore competitively exclude pollinator wasps from fragmented forests. The population of pollinator wasps in primary forest would be expected to be much more stable than in the fragmented forests. Pollinator wasps in fragmented forest may experience localized extinctions more frequently, with re-establishment expected to be facilitated through immigration (Figure 3 ).

\section{Conclusion}

Spatial heterogeneity plays an important role in meta-population creation $[47,48]$. Among habitat sites with spatial heterogeneity, species distributions may differ in density and biodiversity. Spatial heterogeneity is created by physical differences, such as climatic or geographic features, and individuals within a species and/or different species might migrate from their habitats to other colonies. Such physical differences leading to the oscillation of species interactions have been well documented within coevolutionary systems [49,50]. Research into fig-fig wasp systems demonstrates, however, that asymmetric species interactions might also create a meta-population, which is in

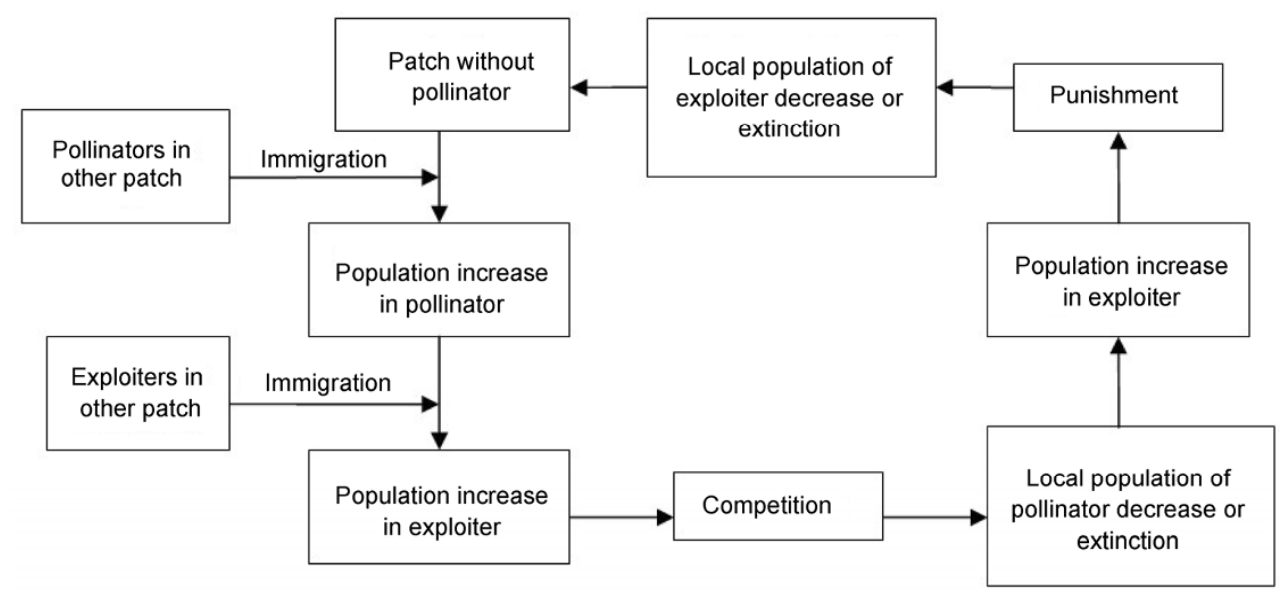

Figure 2 Creation mechanisms of the metapopulation under asymmetric interactions in the fig-fig wasp system. 


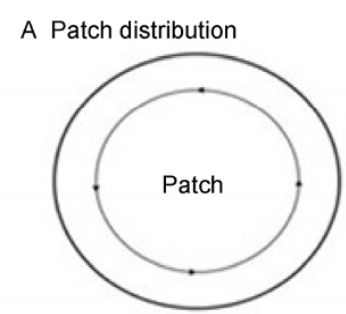

(a) Primary forest

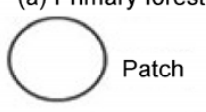

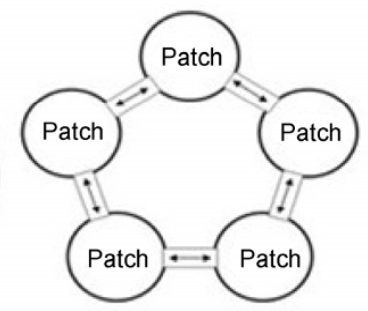

(b) Fragmented forest

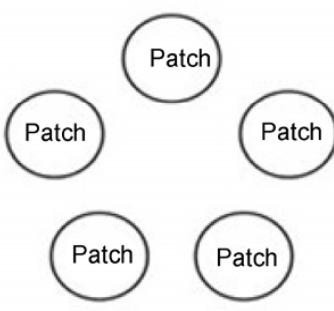

(c) Locally fragmented forest
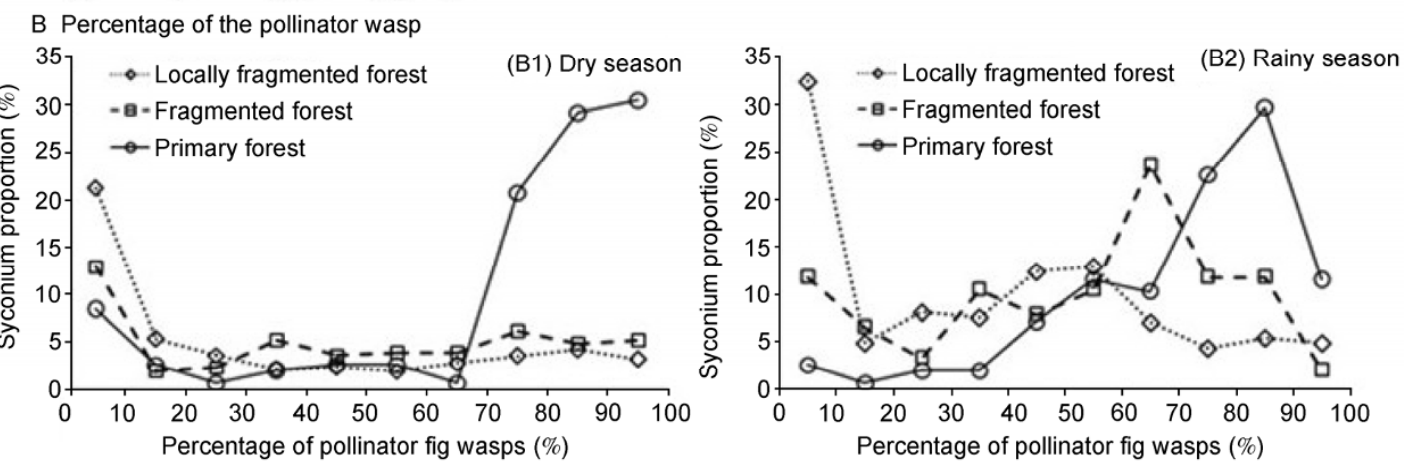

Figure 3 A, Schematic representation of (a) primary forest, (b) fragmented forest with pseudo-corridors, and (c) locally fragmented forest habitat types where observations of pollinator wasp and fig (Ficus racemosa) populations were made (see Wang and Sun, 2009; Wang et al., 2010 for additional details). B, Relationship between the proportion of syconia (\%) and the percentage of pollinator wasps in the $F$. racemosa-fig wasp community across primary forest, fragmented forest and locally fragmented forest habitat types during dry season (B1) and wet season (B2) events. For description of the methods used for data collection see Wang et al. (2010) or Supporting Information.

contrast to the meta-population creation dynamic of spatial heterogeneity.

In fig-fig wasp systems, the species interactions are very specific; in most cases, each wasp species pollinates only one fig species, and each gall maker or parasitic species only parasitizes one fig or wasp species. Within these species communities, one species usually has obvious fitness advantages over another, such as a gall maker among non-pollinator wasps being more competitive than pollinator wasps [28,29,51]. However, the fig plant can alter the behavior of pollinators and gall makers to be less parasitic and/or more cooperative by sanctioning parasitic individuals and rewarding pollinating individuals [14]. In such a closely interactive relationship, the sanctioning of one species against another species, or fitness advantages of one over another, will more easily lead to the population decline or localized extinction of another species [16,52,53]. The sanctioning of one species against another within asymmetric interactions between species with such closer interactions might be much stronger than that between less closely interactive species (Wang et al., unpublished data). In less closely interactive species communities, the population fluctuations of interacting species might be smaller than those in species communities showing more highly asymmetric interactions. The effects of the meta-population might be less significant in these less closely interactive species communities.

In a community with asymmetric species interactions, the limited dispersal ability of individuals within a species and/or spatial correlations between species may play important roles in meta-population creation [52,53]. The greater the degree of difficulty for the dispersal of community individuals, the greater the probability becomes for population declines or local extinctions under asymmetric interactions [14,25]. In a species community, if individuals of interacting species suffer dispersal limitations, the sanctioning of or higher competition of one species over another will more likely result in population declines or localized extinctions of the "weaker" species [14,16,54,55]. Alternatively, weaker species may disperse to other colonies in order to escape sanctioning by the host fig or intense competition presented by the "stronger" species. In a community with less severe dispersal limitations, the population of each species would be predicted to be more evenly distributed among the different habitat patches.

We thank John Thompson and Cheng Lu for their comments and suggested revisions. This work was supported by the National Natural Science Foundation of China (NSFC) (31270433, 31170408), National Science Fund for Distinguished Young Scholars (31325005), NSFC-Yunnan United Fund (U1302267), the West Light Foundation of the Chinese Academy of Sciences, and the Special Fund for the Excellent Youth of the Chinese Academy of Sciences (KSCX2-EW-Q-9). 
1 Thompson JN. Concepts of coevolution. Trends Ecol Evol, 1989, 4: 179-183

2 Weiblen GD. Interspecific coevolution. In: Nature Encyclopedia of Life Sciences. London: Nature Publishing Group, 2003

3 Ehrlich PR, Raven PH. Butterflies and plants: a study in coevolution. Evolution, 1964, 586-608

4 Janzen DH. How to be a fig. Ann Rev Ecol Syst, 1979, 10: 13-51

5 Weiblen GD. How to be a fig wasp. Ann Rev Entomol, 2002, 47: 299-330

6 Ronsted N, Weiblen GD, Cook JM, Salamin N, Machado CA, Savolainen V. 60 million years of co-divergence in the fig-wasp symbiosis. Proc R Soc Lond B, 2005, 272: 2593-2599

7 Freeland W, Janzen DH. Strategies in herbivory by mammals: the role of plant secondary compounds. Am Nat, 1974, 269-289

8 Maynard Smith J. Evolution and the Theory of Games. Cambridge: Cambridge University Press, 1982

9 Janzen DH. When is it coevolution? Evolution, 1980, 34: 611-612

10 Axelrod R, Hamilton WD. The evolution of cooperation. Science, 1981, 211: 1390-1396

11 Weyl EG, Frederickson ME, Douglas WY, Pierce NE. Economic contract theory tests models of mutualism. Proc R Soc Lond B, 2010, 107: $15712-15716$

12 Maynard Smith J. Do animals convey information about their intentions? J Theor Biol, 1982, 97: 1-5

13 Pellmyr O, Huth CJ. Evolutionary stability of mutualism between yuccas and yucca moths. Nature, 1994, 372: 257-260

14 Wang RW, Sun BF, Zheng Q. Diffusive coevolution and mutualism maintenance mechanisms in a fig-fig wasp system. Ecology, 2010, 91: 1308-1316

15 Kiers ET, Rousseau RA, West SA, Denison RF. Host sanctions and the legume-rhizobium mutualism. Nature, 2003, 425: 78-81

16 Wang RW, He JZ, Wang YQ, Shi L, Li YT. Asymmetric interaction will facilitate the evolution of cooperation. Sci China Life Sci, 2010, 53: 1041-1046

17 Yu DW. Parasites of mutualisms. Proc R Soc Lond B, 2001, 72: 529-546

18 Pellmyr O, Leebens-Mack J. Reversal of mutualism as a mechanism for adaptive radiation in yucca moths. Am Nat, 2000, 156: S62-76

19 Pellmyr O, Leebens-Mack J, Huth CJ. Non-mutualistic yucca moths and their evolutionary consequences. Nature, 1996, 380: 155-156

20 Kiers ET, Denison RF. Sanctions, cooperation, and the stability of plant-rhizosphere mutualisms. Ann Rev Ecol Syst, 2008, 39: 215-236

21 Wiebes J. Co-evolution of figs and their insect pollinators. Ann Rev Ecol Syst, 1979, 10: 1-12

22 Wang RW, Shi L, Ai SM, Zheng Q. Trade-off between reciprocal mutualists: local resource availability-oriented interaction in fig/fig wasp mutualism. J Anim Ecol, 2008, 77: 616-623

23 Jousselin E, Hossaert-McKey M, Herre EA, Kjellberg F. Why do fig wasps actively pollinate monoecious figs? Oecologia, 2003, 134: 381-387

24 Jander KC, Herre EA. Host sanctions and pollinator cheating in the fig tree-fig wasp mutualism. Proc R Soc Lond B, 2010, 277: 1481-1488

25 Wang RW, Sun BF, Zheng Q, Shi L, Zhu LX. Asymmetric interaction and indeterminate fitness correlation between cooperative partners in the fig-fig wasp mutualism. J Roy Soc Interface, 2011, 8: 1487-1496

26 Kerdelhue C, Rossi JP, Rasplus JY. Comparative community ecology studies on old world figs and fig wasps. Ecology, 2000, 81: 2832-2849

27 Wang RW, Zheng Q. Structure of a fig wasp community: temporal segregation of oviposition and larval diets. Symbiosis, 2008, 45: 113-116

28 West SA, Herre EA. The ecology of the new-world fig-parasitizing wasps Idarnes and implications for the evolution of the fig-pollinator mutualism. Proc R Soc Lond B, 1994, 258: 67-72

29 Wang RW, Yang CY, Zhao GF, Yang JX. Fragmentation effects on diversity of wasp community and its impact on fig/fig wasp interaction in Ficus racemosa L. J Integr Plant Biol, 2005, 47: 20-26

30 Weiblen GD. Correlated evolution in fig pollination. Sys Biol, 2004, 53: $128-139$

31 Wang RW, Ridley J, Sun BF, Zheng Q, Dunn DW, Cook J, Douglas WY. Interference competition and high temperatures reduce the virulence of fig wasps and stabilize a fig-wasp mutualism. PLoS ONE, 2009, 4: e7802

32 Cook JM, Rasplus JY. Mutualists with attitude: coevolving fig wasps and figs. Trends Ecol Evol, 2003, 18: 241-248

33 Dunn DW, Segar ST, Ridley J, Chan R, Crozier RH, Douglas WY, Cook JM. A role for parasites in stabilising the fig-pollinator mutualism. PLoS Biol, 2008, 6: e59

34 Nefdt RJC, Compton SG. Regulation of seed and pollinator production in the fig fig wasp mutualism. J Anim Ecol, 1996, 65: 170-182

35 Yang C, Wang R, Zhao G, Yang D. Diet of non-pollinating wasps and their impact on the stability of fig-pollinator wasp mutualism. Zool Res, 2005, 26: 379

36 Sun BF, Wang RW, Hu Z. The diet separation of fig wasps and the stability of fig-fig wasp. Biodiversity Sci, 2008, 16: 525-532

37 Sun R. Essentials of Animal Ecology. Beijing: Beijing Normal University, 1992

38 Yu DW, Wilson HB, Pierce NE. An empirical model of species coexistence in a spatially structured environment. Ecology, 2001, 82: 1761-1771

39 Tylianakis JM, Rand TA, Kahmen A, Klein AM, Buchmann N, Perner J, Tscharntke T. Resource heterogeneity moderates the biodiversity-function relationship in real world ecosystems. PLoS Biol, 2008, 6: 947-956

40 Wang RW, Sun BF. Seasonal change in the structure of fig-wasp community and its implication for conservation. Symbiosis, 2009, 47: 77-83

41 Bull JJ, Rice WR. Distinguishing mechanisms for the evolution of co-operation. J Theor Biol, 1991, 149: 63-74

42 Goto R, Okamoto T, Toby KE, Kawakita A, Kato M. Selective flower abortion maintains moth cooperation in a newly discovered pollination mutualism. Ecol Lett, 2010, 13: 321-329

43 Denison RF. Legume sanctions and the evolution of symbiotic cooperation by rhizobia. Am Nat, 2000, 156: 567-576

44 Sun B, Wang $\mathrm{R}$, $\mathrm{Hu} \mathrm{Z}$, Li Y. The relation between two non-pollinating wasps oviposition and the fruit abscission on Ficus racemosa. Acta Ecol Sin, 2009, 29: 1-6

45 Herre EA. Coevolution of reproductive characteristics in 12 species of New World figs and their pollinator wasps. Experientia, 1989, 45: 637-646

46 Segraves KA, Althoff DM, Pellmyr O. The evolutionary ecology of cheating: does superficial oviposition facilitate the evolution of a cheater yucca moth? Ecol Entomol, 2008, 33: 765-770

47 Harrison S, Taylor AD, Hanski I, Gilpin M. Empirical evidence for metapopulation dynamics. In: Hanski I, Gilpin ME, eds. Metapopulation Biology: Ecology, Genetics, and Evolution. London: Academic Press, 1997. 27-42

48 Hanski I, Gilpin ME. Metapopulation biology: ecology, genetics, and evolution: Academic press San Diego, California. 1997

49 Thompson JN, Fernandez CC. Temporal dynamics of antagonism and mutualism in a geographically variable plant-insect interaction. Ecology, 2006, 87: 103-112

50 Piculell BJ, Hoeksema JD, Thompson JN. Interactions of biotic and abiotic environmental factors in an ectomycorrhizal symbiosis, and the potential for selection mosaics. BMC Biol, 2006, 6

51 Wang RW, Yang JX, Yang DR. Seasonal changes in the trade-off among fig-supported wasps and viable seeds in figs and their evolutionary implications. J Integr Plant Biol, 2005, 47: 144-152

52 West SA, Kiers ET, Pen I, Denison RF. Sanctions and mutualism 
stability: when should less beneficial mutualists be tolerated? J Evol Biol, 2002, 15: 830-837

53 Wang RW, Dunn DW, Sun BF. Discriminative host sanctions in a fig-wasp mutualism. Ecology, 2013, doi: 10.1890/13-0749.1
54 Doebeli M, Knowlton N. The evolution of interspecific mutualisms. Proc Natl Acad Sci USA,1998, 95: 8676-8680

55 Wang RW, Shi L. The evolution of cooperation in asymmetric systems. Sci China Life Sci, 2010, 53: 139-149

Open Access This article is distributed under the terms of the Creative Commons Attribution License which permits any use, distribution, and reproduction in any medium, provided the original author(s) and source are credited.

\section{Supporting Information}

\section{The method of data collection presented in Figure 3}

We collected adult wasps that were supported by figs from three sampling sites. One sample site was at the center of the primary forest, and another was at the edge of the primary forest, within a locally fragmented forest. Samples were also collected from a highly fragmented forest where the fig plants are isolated by rubber trees, roads or crop fields. We collected these data over most months of the year in 2006, 2007 and 2008. The total sample size was $N=1503$.

When the syconia developed to maturity, but before pollinator wasps cut open exit holes, we collected mature syconia and injected $75 \%$ alcohol to kill all adult wasps present in the syconium. We then counted both male and female wasps present in each syconium. In this data census, we cut open galls to collect adult wasps-if wasps did not exit the galls we ensured that the data generated from adult wasps included all of the well-developed adult wasps present.

The supporting information is available online at life.scichina.com and link.springer.com. The supporting materials are published as submitted, without typesetting or editing. The responsibility for scientific accuracy and content remains entirely with the authors. 